\title{
Ethics and the Practice of Primary Care Psychiatry
}

\author{
Russell H. Searight \\ Department of Psychology, \\ Lake Superior State University, \\ USA
}

\section{Introduction}

\subsection{Psychiatric conditions in primary care}

In the United States, as in many Western countries, the primary care clinic has become a very common site for diagnosis and treatment of psychiatric conditions. There has been a significant increase in mental health care visits in the primary care sector. In the 1980s, slightly over $40 \%$ of patients receiving mental health care were diagnosed and treated by primary care physicians. Of this patient population, $75 \%$ were managed solely by primary care physicians without psychiatric or psychological consultation (Kessler, Demler, Frank, et al., 2005; Wang, Demler, Olfson, et al., 2006). Between the 1980s and 2010, the use of primary medical care for mental health services has increased by over $150 \%$. By 2008 , the primary care sector had become the the most common treatment setting for mental health problems in the United States (Cwikel, et al., 2008). For example, 50\% of all patients in the U.S. treated for major depressive disorder are managed solely in the primary care sector. These physicians spend a total of 12.1 hours per week--nearly a quarter of their direct patient contact hours--providing mental health services. In the U.S., approximately $20 \%$ of psychotherapy sessions are provided by primary care physicians (Himelhoch \& Ehrenreich, 2007). In the United Kingdom, mental health counseling is also a major activity among general practitioners. This surge occurred in the context of corresponding increases in the percentage of the general population receiving mental health care-from $12 \%$ per year in 1990-92 to 20\% by 2000-2001 (Kessler, Demler, Frank, Olfson, et al., 2005).

Even with this level of psychiatric care by primary care providers, there is considerable evidence of a greater need for mental health care among their patients. Psychiatric symptoms are very common in primary care settings. When compared with the general population, primary care patients have elevated levels of psychiatric symptoms. An early large-scale survey of primary care patients found that approximately $20 \%$ of them had a current psychiatric condition (Barrett, Barrett, Oxman, \& Gerber, 1988) with major depressive and anxiety disorders the most common. An additional $11 \%$ were diagnosed with another psychiatric condition. However some of these patients did have depressive symptoms as well. Generalized anxiety disorder was the second most common mental health diagnosis. Of note, when examining the presence of symptoms rather than specific 
conditions, only $30 \%$ of this primary care population was psychiatrically symptom-free with approximately $40 \%$ exhibiting mild symptoms (Barrett, et al., 1998).

More recent studies suggest that rates of psychiatric distress in primary care are rising. When examining the prevalence of mental health conditions in primary care patients during the past year, Cwik et al. (2008) found that approximately half of all patients had some type of significant psychiatric symptomatology. Women were more likely $(54.8 \%)$ than men $(44.9 \%)$ to be exhibiting significant psychiatric distress. When formal criteria from the Diagnostic and Statistical Manual of Mental Disorders (American Psychiatric Association, 2006) were applied, $26 \%$ of men and $34 \%$ of women had a mood, anxiety, or eating disorder and/ or somatoform disorder. While mood disorders were the most common with $17.4 \%$ of men and $22.2 \%$ of women meeting criteria for major depression during the past year, anxiety disorders were a close second with $13.5 \%$ of men and $20 \%$ of women having at least one of these disorders during the past year (Cswik et al., , 2008; Searight, 2010). With respect to anxiety disorders, among a large sample of primary care patients, $20 \%$ of them currently met criteria for at least one anxiety disorder with $8.6 \%$ exhibiting posttraumatic stress and $7.6 \%$ exhibiting generalized anxiety and finally, $6.8 \%$ demonstrated panic disorder (Kroenke, Spitzer, Williams, et al., 2007). Among pediatric patients, the majority of diagnoses of attention deficit hyperactivity disorder are made by pediatricians and family physicians. When examined from the perspective of sheer numbers, the majority of prescriptions for stimulant medication used to treat the condition are also written by primary care physicians (Mayes, Bagwell, Erkulwater, 2009).

\subsection{Reasons behind the rise of primary care psychiatry}

There are probably multiple reasons for the increase in the practice of primary care mental health in the past three decades. First, there is evidence that the rates of significant psychiatric conditions such as mood and personality disorders are increasing (World Health Organization., 2011). Second, in many universal healthcare systems as well as the in many insurance and/or managed-care plans, primary care physicians are the gatekeepers to specialty care including psychiatry (Bryan \& Rudd, 2011).

Third, there has been increased attention to educating primary care physicians about mental health problems. As a result, while they still miss up to half of patients with conditions such as depression and anxiety disorders, their level of competence in assessing these patients has improved. Fourth, the availability of second generation SSRI antidepressants with relatively few side effects have made many physicians more comfortable with treating psychiatric conditions. Efforts by the pharmaceutical companies to educate primary care physicians by providing information about efficient assessment strategies such as patient self-report instruments has made diagnosis somewhat easier (Bryan \& Rudd, 2011). Additionally, pharmacotherapy regimens became safer and guidelines for psychotropic medication use have raised non-psychiatric physicians' comfort level with this treatment modality. Because of direct to consumer marketing of psychotropic medications, the general public has become more aware of mental disorders and the availability of treatment. Finally, there continue to be a number of systems barriers to accessing specialty mental health care. In countries such as the U.S., insurance companies have "carved out" specialty mental health services so that access is governed by different procedures than for medical care. In countries such as Canada, with government-funded universal coverage, access to specialty 
care is often associated with lengthy waiting periods because of the limited number of specialists including psychiatrists and psychologists.

\subsection{The role of chronic disease}

Another, often unrecognized, factor in the rise of primary care mental health has been the shift from infectious disease to chronic conditions such as Type II diabetes and cardiovascular disease. These conditions are associated with increased levels of psychiatric distress which both directly and indirectly impact theses medical conditions. For example, the presence of major depressive disorder is associated with a three-fold increase in health care non-adherence including issues such as maintaining an appropriate diet and taking medication according to a prescribed schedule (Di Matteo, 2006). The etiology of these common primary care conditions are influenced by lifestyle factors such as physical activity, smoking, alcohol use, and consumption of dietary fat.

\subsection{New ethical dilemmas}

While psychiatric care has become commonplace in general medicine, a neglected aspect has been the distinctive ethical and professional dilemmas arising when treating patients' mental health problems. As will be discussed below, virtue-based ethical guidelines such as the Hippocratic Oath and formal codes such as the American Medical Association's "Principles of Medical Ethics," do not adequately address common professional and ethical issues arising in providing psychiatric care. For example, while treating colleagues and their families is common for primary care physicians, this practice is strongly discouraged by the American Psychological Association's Ethical Code (Koocher \& Keith-Spiegel, 2008).

\section{Ethical principles}

In much of the western world, there are two prevailing models of medical ethics. The first approach derives from the Hippocratic oath and articulates the virtues of a moral healthcare provider. The second model, principlism, provides a four dimensional framework for analyzing clinical situations. Principlism emphasizes a somewhat detached analysis of ethical dilemmas according to these dimensions.

\subsection{Virtue ethics}

The first approach, that has a much longer history in biomedicine, is that of virtues. The Hippocratic Oath, a virtue based code, has a long history in medicine. The Oath essentially states what a good physician does ("Whatever houses I may visit, I will come for the benefit of the sick, remaining free of all intentional injustice, of all mischief in particular of sexual relations with both female and male persons, be they free or slaves.").

A contemporary perspective on physician virtues has been described by Pellegrino and Thomasma (1998). These medical ethicists believe that virtues can and should be formally taught to physicians-in-training. Additionally, these virtues typically go beyond the role of physician and encompass what a morally responsible individual would do during the course of their lives. Pellegrino and Mann's virtues include intellectual honesty, benevolence, humility, and therapeutic parsimony. Additional virtues include trust, compassion, prudence, justice, fortitude, temperance, integrity and self-effacement. A key 
virtue for ethical issues in health care is Prudence - the ability to reason reflectively and respond to concrete life dilemmas in a way that is both technically and morally correct (Pelligrino \& Thomasma, 1998).

\subsection{Principlism}

In contrast, principlism, rather than focusing on the health care provider's character or actions, centers on four abstract dimensions. These dimensions include: respect for autonomy, nonmaleficence, beneficence, and justice.

Respect for autonomy involves a level of self-determination undisturbed by others' control or influence. Autonomy presumes that one is capable of deliberating and/or acting on the basis of their personally-held wishes, plans and values. It has been argued that geunuine autonomy requires that the individual have all relevant knowledge necessary for making a decision about their own welfare. In most parts of the world, the consent form, signed by the patient before any medical procedure is undertaken, is seen as "proof" of autonomous decision-making. .

Nonmaleficence is best summarized by the medical dictum "first, do no harm." Beauchamp and Childress argue that obligations for nonmaleficence are usually more "stringent" than helping or promoting the welfare of another. An example of their perspective is the general acceptance by the medical community of the decision by a competent patient to refuse a lifesustaining treatment such as ventilator support. However, removal of a ventilator from a living patient typically requires a higher level of critical analysis. In the latter situation, Beauchamp and Childress (2009) believe that there is more of a direct causal connection between a harmful outcome stemming from stopping treatment than in failing to initiate therapy.

Beneficence refers to contributing to the welfare of others. In contrast to nonmaleficence, healthcare providers should take positive proactive steps to benefit patients and not just shield them from harm. A current ethical conflict is when providers believe that an intervention, such as childhood immunizations, is in the patient's best interest while the child's parent disagrees because of concerns about side effects. In many instances, the patient's autonomy over-rules the physician's duty to act to protect patient welfare.

Justice refers to fair, equitable, and appropriate treatment in the context of what is owed to an individual. A close corollary is the concept of distributive justice in which there is a fair distribution of rights, responsibilities, and benefits. In the United States, for example, a key public health problem has been that of health disparities. There is ample evidence that people of all ethnic and social backgrounds do not have equal access to healthcare and are not given the same level of treatment. This pattern exists for multiple medical treatments ranging from pain management, to mental health referrals, to coronary artery bypass graft surgery.

One of the most frequent criticisms of principlism is that while it provides a useful and relatively simple framework for analyzing ethical dilemmas in medicine, it does not inherently lead to definite courses of action. A chief reason for this lack of direction is that there is no priority among the four dimensions and at times, principles may be in conflict. For example, providing contraceptive information and care to a 15-year-old girl, raises 
questions about the patient's autonomy (Is she cognitively and developmentally capable of making well-reasoned decisions?), non-maleficence (Is she aware of and able to appropriately act on any risks associated with contraception such as a greater likelihood of blood clots if she is a smoker ?), beneficence (It is assumed that protection from pregnancy is beneficial to the young woman. Evidence about the adverse effects of teen pregnancy and motherhood would support this view) and justice (Is contraceptive care something that her peers would be able to access as easily?). In this illustration, there is a potential conflict between autonomy and beneficence. Well-meaning parents may assert that their daughter does not have the necessary cognitive capacity or psychosocial maturity to make truly autonomous decisions about either sexual relationships or contraception. From the perspective of beneficence, there is the value that she should be protected from the "harm" of unintended pregnancy associated with sexual activity.

\subsection{Ethics in the mental health professions}

In the mental health professions, a much more detailed code of ethics has evolved. For example, psychiatry has an annotated set of ethical principles along with those of the American Medical Association (American Medical Association, 2001). Similarly, for psychologists, the American Psychological Association's ethical guidelines for practitioners are much more detailed and explicit than for researchers and teachers. These guidelines examine issues such as confidentiality, competence to practice, conflicts of interest, dual relationships, and duties to protect others from patients who are potentially violent or are otherwise, presenting risks of harm. For example, AMA's psychiatric annotations include specific circumstances in which confidentiality may be breached. In the discussion of dual relationships, the annotations note that psychiatric care is such that "essentially private, highly personal and sometimes intensely emotional material" may arise in the clinical relationship, raising risks of impaired provider objectivity.

The American Psychological Association's (2002) Code of Ethics examines dual relationships in even more detail. In elaborations of APA's guidelines, the distinction between a "personal" and a "psychologist-patient" relationship is described. In the analysis, it is noted that successful personal relationships are oriented toward mutual satisfaction and addressing common needs (Koocher \& Keith-Spiegel, 2008). Furthermore, it is noted that agendas in personal relationships are not necessarily associated with attaining specific goals. In contrast, the professional relationship between psychologist and patient is not mutual; it arises to serve the needs of the client with a focus on specific therapeutic goals. Once those goals are attained, termination of the relationship is expected. Socializing and entering into friendships with current, and frequently, with past patients is strongly discouraged. In addition, treating the relatives of patients is also strongly discouraged (Koocher \& KeithSpeigel, 2008).

\subsection{Mental health ethics and primary care}

These examples highlight the inherent ambiguity and complexity of ethical issues that may arise in treating psychiatric conditions in the primary care sector. In essence, the primary care physician becomes the "functional equivalent" of a mental health professional in these clinical encounters. However, ethical dilemmas such as circumstances mandating the breaking of 
patient confidentiality, responding to third party requests for patients' mental health information (including that of minors), duties to protect third parties and the community-atlarge, as well as the boundaries of the physician-patient relationship, do not commonly arise in general medical practice. While mental health professionals typically have had significant didactic coursework as well as supervised clinical training in examining these complex ethical issues, primary care physicians are typically only aware of the more concise, yet general, principles governing general medical practice. The practice of psychiatry by primary care physicians, itself, raises questions about practicing outside the bounds of professional competence. Finally, psychiatric symptoms among primary care patients are often difficult to assess because they are non-specific, based solely on patient report, and frequently co-exist with organic medical conditions. This often leaves the provider with having to diagnose and initiate treatment with a less than optimal diagnostic foundation.

\section{Confidentiality}

\subsection{Mental health content in the medical record}

Patients with mental health issues seen in the primary care sector often present with nonspecific physical complaints and frequently have comorbid medical illnesses. As a result, medical records may include both information about acute and chronic illnesses, such as hypertension and type II diabetes, but also include psychiatric diagnosis and treatment information. There are a number of situations in which patients' records may be disclosed to third parties including insurance companies, government agencies, attorneys, surrogate medical decision makers, and in the case of minors, parents. Patients, themselves, are often unaware that mental health information may have been documented and may authorize release of their medical record with little reflection on the potential implications. While there is typically little stigma associated with most problems diagnosed and treated in ambulatory primary care, the same cannot be said for mental health issues. Disclosure of mental health information can prevent patients from obtaining health and life insurance, adopting a child, entering the military, and could conceivably have negative effects on current and future employment. Additionally, records of mental health treatment are commonly sought in divorce and child custody legal actions. In these circumstances, the physician should rely on beneficence and non-maleficence by informing the patient of the information in the record and ask if they would still want to share the material with a third party. Without knowledge of the medical record itself and/or its use in these non-medical contexts, the patient cannot make a truly informed, autonomous decision.

When surveyed confidentially, a sample of U.S. general practitioners reported that the issue of external review of records influenced them to misrepresent information in the patient's record, itself. In addition, many of these physicians indicated that they had protected patient privacy by misrepresenting or omitting information on insurance forms. In this survey, $21 \%$ of the physicians sampled failed to report illness, such as sexually transmitted diseases, to the local health department (Ullom-Minnich \& Kallial, 1993; Roberts, Battaglia, \& Epstein, 1999).

\subsection{Minors}

In both medicine and mental health, issues of informed consent and confidentiality for minors are often areas in which ethics and law conflict. Ethical reasoning is also challenged 
since the child, rather than their parent or guardian, is the patient whose well-being is entrusted to the physician. Because of cognitive-developmental factors, minors may not be able to engage in the level of reasoning required to make truly informed decisions about their medical or mental health care. Therefore, from Beauchamp and Childress' (2009) perspective, children and some adolescents have inherently diminished autonomy. However, per Pellegrino and Thomasma (1998), the health care provider has a responsibility to establish a trusting relationship and represent the best interests of their young patients.

With a few exceptions, parents generally have legal rights to any information, including medical and mental health records, about their minor children. Additionally, parents and guardians typically have the right to make health care decisions on their child's behalf and can override children's objections or requests. However, there are circumstances in which the physician and parents may differ regarding the child-patient's best interests. Historically, the major controversies arising in primary care around this ethical-legal tension have been those involving sexuality and substance abuse among minors. Many states in the United States have passed laws that include an exception to parental notification so that minors (typically 14, 15, or 16 years old) can seek contraceptive care and also mental health/substance abuse counseling without informing a parent or guardian. These laws, reflecting beneficence, recognize that many minors would be disinclined to seek treatment for these issues if parental notification and disclosure of the material shared with the physician were required. While there are situations in which prescribing contraception may increase risk of adverse outcomes outcomes (birth control pills prescribed to an adolescent who smokes cigarettes), the most pressing issue from the parental perspective is that this risk behavior could potentially be harmful to the minor. If parents are unaware of their child's status with respect to sexual activity or drug use, appropriate parental supervision may not be initiated. In the United Kingdom, persons 16 and older are assumed to have the capacity to provide valid consent (Tan, Passerini, \& Stewart, 2007). However, research has suggested that younger adolescents and children of average to above average intelligence may have the cognitive capacity to make these decisions as well.

\subsection{Psychotropic medication and children}

With respect to psychiatric care, there have been growing concerns about the large number of children and adolescents who are being prescribed psychotropic medications. For example, the majority of prescriptions for stimulant medications are written by primary care physicians such as family physicians and pediatricians rather than by child psychiatrists. Both law and ethics, based on the principle of autonomy, recognize that competent adults, even when exhibiting overt psychiatric symptomatology, can refuse psychotropic medication. This issue has not been explored with respect to children. It is not uncommon for children to express discomfort about taking medications such as methylphenidate because it makes them feel "different" than their peers and implicitly stigmatized. Additionally, while not as common, concerns about difficulty falling asleep, suppressed appetite, and headaches, are also expressed by children taking stimulant medication.

An alternative to consent that has been suggested in working with minors is that of "assent." Assent essentially means that the child has not overtly objected to the treatment recommendations. Their agreement is often inferred from the child's cooperation with parents and the healthcare provider (Tan, Passerini, \& Stewart, 2007). When children are 
raising objections to taking or continuing psychotropic medication, the provider, while attempting to understand and respect the child's reluctance, should also determine the level of risk and treatment urgency involved. There is a corresponding duty of care (beneficence) that should be enacted while maintaining openness to the perspective of the young patient and their family and minimizing coercion.

While focused issues of family planning have often been granted confidentiality with adolescents, this level of confidentiality my not always in the child's best interest when other mental health issues are being addressed (Tan, et al., 2007). First, it is often necessary for parents to monitor the child's behavior and provide the prescribing physician feedback about the patient's behavioral response to stimulant medication. Studies of children with ADHD suggest that they are not accurate self-observers (Searight, Gafford, \& Evans, 1998). Additionally, information about the child's performance in school is also critical for assessment as well as for medication management. Optimally, the child should be informed that others will be reporting on their behavior and unless disclosure of information is seen as potentially harmful to the child, the child should be tactfully informed about others' reports of their conduct while being encouraged to offer their own perspective. This open communication policy is particularly important with adolescents since "secret information" about their behavior may seriously damage the provider-patient relationship.

\subsection{Child custody issues}

Because of their increasing involvement in treating child mental health conditions, primary care providers may become entangled in legal issues in which the confidentiality of a child's psychiatric information may be compromised. Common situations are custody issues in which one parent reports that the child has been either abused or exposed to neglectful supervision while in the other parent's care. The physician may be subpoenaed by the court to provide an opinion about the veracity of these reports - particularly if the disclosures are by the child. Again, forcible disclosures may harm the child's relationship with one or both parents and in some circumstances, could put the child at risk for abuse. This is a situation in which the child's welfare may be best served by refusing to disclose this information on therapeutic grounds.

Among children receiving stimulant treatment for $\mathrm{AD} / \mathrm{HD}$, it is not uncommon for separated or divorced parents to disagree about the need for the medication. Again, from an ethical perspective, the physician's first priority is the welfare of the child. In joint custody situations or situations involving a noncustodial parent who disagrees with the treatment being provided by the physician, it is often a useful idea to invite them in for an appointment to discuss the child. Again, in circumstances in which there is joint custody or in which the physician is going to be meeting with a noncustodial parent, they should have written permission from the other parent to initiate and conduct a conference at this time. Finally, in situations in which records about a pediatric patient are requested in a legal context and there is significant judicial pressure to comply, there are several avenues that the physician can employ to benefit patient confidentiality and limit disclosures. First, the provider can send a letter which addresses specific questions raised in a legal context while disclosing minimal amounts of background information. Second, the provider can simply refuse to provide information insisting that disclosure would be harmful to the child. Finally, in a compromise solution, the physician may indicate that they can describe and 
respond to general questions about a particular mental health condition such as ADHD or childhood mood disorder without specific reference to the patient.

\section{Dual relationships}

\subsection{Providing mental health care to patients who are family friends and colleagues}

Mental health education devotes considerable time to the importance of clear roles and professional boundaries. Ethical psychologists would never provide psychotherapy for family or friends. While mental health professionals may have informal conversations with colleagues or office staff about personal and family matters, psychologists and psychiatrists are discouraged from providing professional services to persons with whom they have another relationship - even if their sole contact is as a secretary or receptionist in their large group practice. Primary care physicians, while discouraged from treating friends and family, do not have the same degree of prohibition as psychologists regarding dual relationships. It is not uncommon for physicians to be the personal physician for office staff or even colleagues. Indeed, many physicians either formally or informally provide professional care for family and friends. While treating family members is discouraged; it is not unusual for physicians to treat other physicians that they know, family members of colleagues, as well as employees of their hospital or clinic.

Dual relationships are a particularly challenging issue in smaller communities and rural areas. A survey of general practitioners in Kansas found that nearly half of the physicians practicing in small communities reported having a significant number of patients who were family members, friends, or family members or friends of the physician's staff. Most of the small town physicians surveyed indicated that they had interacted in non-medical roles with patients (Roberts, Battaglia, \& Epstein, 1999; Ullom-Minnich \& Kallall, 1993).

While there are guidelines established by the American Medical Association for ethical practice, they are not as specific as the American Psychological Association's Ethical Principles in influencing practice or state licensing boards. In addition, the guidelines for non-psychiatric physicians are not nearly as stringent regarding multiple relationships with patients.

The rationale for not providing mental health care to members of one's social network is predicated on the recognition of the intensely emotional and personal nature of the psychotherapeutic relationship. If the provider has another personal or professional relationship with the patient, the patient may be reluctant to disclose concerns such as sexual dysfunction, marital conflicts, substance abuse or suicidal ideation. The rationale is that it would be particularly challenging to maintain appropriate personal-professional boundaries and it would be difficult for this knowledge not to impact the social relationship between physician and patient when they are outside of those roles. Family physicians have been found legally liable when counseling a patient for marital issues and then entering into a sexual relationship with one of the spouses. In these circumstances, it would be difficult not to use the personal information received in counseling to assist in establishing an intimate relationship (Searight \& Campbell, 1993). The category of inappropriate dual relationships is one of the most common sources of malpractice litigation and complaints to ethics boards for psychiatrist and psychologists. 


\subsection{The sick note}

A potential for dual relationships and competing priorities occurs when physicians communicate with patients' employers. Often, only medically-authorized absences from work or school prevent loss of pay, a failing grade, or termination of employment. A common term used for a physician provided work excuse is the "sick note." As employment has become scarcer with recent economic downturns, patients are even more likely to request physician documentation of their time off of work to maintain wages and avoid termination. Primary care physicians are well aware of the negative effects of remaining in the sick role for extended periods of time. For example it is relatively well-established that previously employed patients with chronic low back pain are unlikely to ever return to work if they are away from their job for six months or more. Ideally, there would be an interaction between the physician and employer in which work duties could be modified and phased in so as to permit an earlier return to work and reduce the likelihood of the patient being permanently disabled.

From an ethical point of view, the sick note raises both anxiety and frustration for physicians. This is particularly true for sick notes based on psychiatric disability. The subjective nature of mental health complaints and the waxing and waning pattern of symptoms make professional judgment about work-related duties particularly challenging. In addition, healthcare providers tend to have a fairly pronounced work ethic and are likely to be troubled by seemingly physically healthy patients who are seeking their assistance to avoid returning to work. Although paternalistic, a beneficent physician's encouragement to return to work may be guided by a belief that employment would be beneficial to the patient's emotional, and likely, physical health . On the other hand, if the physician views the patient as an autonomous agent who can make decisions about return to work alone, the physician is likely to see their role as simply to document and support the patient's request. However, in addition to their views about the potential longer-range benefits of returning to work, physicians may understandably chafe at supporting unhealthy behavior (nonmaleficence) with a sick note

Finally, many physicians see themselves as inadequately trained to perform evaluations for the workplace. From the perspective of occupational health, a well-documented rationale for sending a patient back to work would include an appreciation of the patient's specific expected duties as well as the environment in which these activities occur. In circumstances where the physician is a contracted Workmen's Compensation provider or company physician, there may be pronounced conflicts of interest between the patient's well-being and that of the physician's employer.

In disability dilemmas involving psychiatric conditions, physicians are encouraged to use objective standards in evaluating the patient's current condition. For example, for major depressive disorder, having the patient complete a standardized rating scale such as the Beck Depression Scale or Hamilton Depression Rating Scale prior to initiating pharmacotherapy and at regular intervals thereafter, can assist the physician by having some objective quantitative standards that are used to assess the patient's current functioning. The Global Assessment of Functioning (GAF) index from the DSM-IV (axis V) provides another useful source of quantitative ratings. 
In circumstances in which the patient, workplace representative, and the physician disagree on the patient's ability to return to work, the physician should describe the patient's current level of functioning. If the patient disagrees about their current capacity for work duties, the patient's judgment can also be reported. This approach permits the physician to operate with professional integrity while the patient's perspective is still represented. The final decision would be made by the patient's workplace administrator.

\section{Dangerous situations}

\subsection{Suicidal patients}

Approximately half of all individuals in the United States who effect suicide have seen a primary care provider in the past month (Bryan \& Rudd, 2011). Among elderly individuals completing suicide, nearly half of had seen their primary care provider in the preceding week. There is considerable evidence that as physical complaints increase, particularly pain, suicide risk increases (Bryan \& Rudd, 2011). When patients are actively suicidal and in need of close monitoring, it is often helpful to notify competent adults with whom the patient resides. This is particularly true in situations in which hospitalization does not appear to be imminently indicated but could possibly be required in the near future if the patient continues to deteriorate. In general, primary care patients will agree to allow notification of family members about their status, provided it is done in a sensitive manner. While the disclosure may somewhat diminish their autonomy, the benefits of informing family almost always outweigh any harm from sharing personal information. Finally, if patients are acutely suicidal, yet are refusing hospitalization, the provider is required to do whatever is reasonably necessary to maintain their safety with confidentiality, at least temporarily, a secondary concern.

\subsection{Duty to warn/protect}

The ethical mandate to protect the public has a long history in the field of public health. The requirement for reporting of sexually transmitted diseases to governmental agencies such as health departments and the use of epidemiological techniques such as contact tracing is well established. In these circumstances, the principal requirement is to notify persons who may have had contact with the infected individual. This general approach has been used for tuberculosis, HIV as well as syphilis and gonorrhea (Sugarman, 2000). The ethical justification in these cases is that the public's well-being outweighs individual confidentiality (Sugarman, 2000).

The involvement of primary care providers in psychiatry has opened up a number of other applications of the duty to warn or protect. Among these, are laws requiring that physicians report suspected child abuse or neglect. Recently, there has also been concern about whether women who are engaging in behavior that places their developing fetus at risk, such as consuming alcohol, should be reported to protective services. Many states have requirements that suspected harm to vulnerable elders is also reported to a state protective services agency-- typically a division of aging. Finally, several states have passed legislation requiring the authorities to be notified if the physician has reason to believe that a patient has sustained injuries associated with partner abuse. 


\subsection{The basis of the duty to protect in psychiatry}

In psychiatry, there is a well-established duty to warn and/or protect. This duty stems from a legal case, Tarasoff versus the Regents of the University of California. In this case, a graduate student at the University of California, Prosenjit Poddar had seen a psychologist at the University clinic. He indicated that he planned to kill a woman who was identifiable as Tatiana Tarasoff. The psychologist notified the campus police but they only held Poddar briefly. Ms. Tarasoff and family were never informed of the threats that had been made. Two months later, Poddar stabbed her to death. Tarasoff's family sued the University. The California Supreme Court concluded that the psychologist had a duty to warn an identifiable intended victim. A subsequent rehearing of the case resulted in a somewhat broader decision termed Tarasoff II. This second decision concluded that there was both a duty to warn as well as a broader duty to protect. In psychiatric case law, mental health providers have been found negligent even in situations in which an intended victim was never formally named. In addition, liability has been imposed in cases in which patients with schizophrenia, months after their last clinical contact, accidentally killed another party in a traffic accident (Searight, 1997).

The concept of the duty to protect has been applied to HIV-positive patients who continue to be sexually active, without informing partners of their status or using condoms. Preventive detention in the form of quarantine has been imposed in some situations of nonadherent patients with serious communicable diseases. This rationale has also been applied to situations in which patients with significant psychiatric and neurological issues such as schizophrenia or seizure disorders were continuing to operate motor vehicles.

Recently, because of the growing aging population, there has been increased concern about harm to others associated with aging drivers. Many older individuals continue to drive despite conditions such as Alzheimer's disease as well as age related medical conditions such as glaucoma. If the physician recommends to the patient that they no longer drive and the patient concurs with agreement that appears to be valid, the physician probably has no further ethical or legal obligation. However, in circumstances in which patients continue to drive despite these impairments, the principle of maleficence indicates an ethical duty to protect the public. A number of jurisdictions have passed laws requiring that physicians report possible impaired drivers to the division of motor vehicles or the government agency which licenses drivers in a particular jurisdiction. These offices in turn should mandate that the patient undergo some type of assessment regarding their driving or forgo their driver's license.

\section{Ethical issues in primary care geriatrics}

\subsection{Capacity for making medical decisions}

Another issue that disproportionately impacts elderly primary care patients is decisionmaking capacity--particularly for health care. Patients refusing treatment for a lifethreatening medical condition raise both ethical and legal liability issues. Physicians may be held liable and viewed as failing to act with beneficence for not treating an incompetent patient refusing a procedure in which the absence of the procedure results in death or further disability. However, a physician may be held legally liable and would be seen as violating patient autonomy if they perform a procedure on a competent patient refusing 
treatment (Searight \& Montooth, 2008). Legally a physician's or psychologist's determination of incapacity is usually required before a written advanced directive or durable power of attorney can be acted upon.

In general medical hospitals and occasionally, in outpatient clinics, capacity determinations are often informally conducted. Searight (1992) suggested that the primary care provider, who has known the patient for some time, may be better suited for rendering opinions regarding capacity than a mental health professional. When the patient does not appear cognitively intact or capable of making reasonable decisions, health care providers often turn to the next of kin for decisions

Capacity decisions are heavily focused on patients' ability to make autonomous, wellreasoned judgments (Grisso \& Appelbaum, 1988). A four-part framework is often used to conduct these assessments. First, the patient should be able to express a consistent choice. Clinically, this component may involve the patient indicating that they are choosing or refusing a proposed intervention. Patients who repeatedly reverse themselves are often unable to maintain adequate attention or concentration to cognitively process medicallyrelevant information. The second aspect, demonstrating an understanding of the current situation, is often assessed by asking the patient to describe "in their own words" the recommended medical procedure. Appreciating information refers to the ability to articulate personal consequences of treatment options including no treatment. The ability to actively weigh treatment options is typically a higher standard assessed when patients are refusing an effective treatment and in which the refusal could reasonably result in further disability or death (Grisso \& Appelbaum, 1988).

\subsection{Physician hastened death}

While a source of continuing controversy, physician assisted suicide or euthanasia is legal in several European countries including Switzerland and the Netherlands. In the United States, three states have passed laws permitting some form of physician assisted hastened death. Ruijs and colleagues (2011) note that many of the patients requesting hastened deathparticularly those with cancer - are attended by primary care physicians. In the Netherlands in recent years close to $90 \%$ of cases of physician assisted suicide were performed by generalist physicians. The majority of their Dutch patients had cancer (Ruijs, et al., 2011). There has been considerable controversy about the criteria that are appropriate for assisting a patient in hastened death.

There is general agreement that patients should be assessed for psychiatric conditions such as major depressive disorder that may be impacting their decision. In addition, appropriate pain control - particularly for patients with cancer-- is an important dimension that should be investigated as part of any hastened death request.

In terminally ill patients, assessment of depression can be an area of ambiguity. A number of the symptoms such as fatigue, sleep difficulty, appetite and weight changes as well as concentration difficulties may not be due to a mood disorder but instead are part of primary illnesses such as cancer or medication to treat the condition.. A further complication is that depression has been construed as either a continuous or a categorical condition. Mood disorders may reflect a continuous set of symptoms as in self-report scales such as the Geriatric Depression Scale in which patients above a particular cutoff score are seen as 
having a particular level of depressive symptoms ranging from mild to severe. The DSMIVTR, on the other hand is a categorical system, and views major depressive disorder as a diagnosis when five of nine symptoms are present for two weeks. Research to date on the prevalence of depression among patients requesting PAS has been conflicting. Several studies have indicated that there is a fairly direct relationship between depressive symptoms among cancer patients and a desire for hastened death. However, this finding has not been consistent (Ruijs et al., 2011

\section{Professional competence for diagnosing and treating mental health conditions}

Because they frequently practice in areas such as rural locations, inner-city settings, and public health clinics, primary care physicians provide a good deal of care to populations that have historically been underserved. These settings often have minimal or inaccessible mental health specialty services. Roberts, Battaglia, and Epstein (1999) point out that in rural communities, there are often significant shortages of qualified mental health professionals, minimal psychiatric inpatient and emergency psychiatric services, and poorly integrated systems of medical and mental health care.

As was noted in the introductory section of this chapter, the prevalence of mental health conditions is very high - it is estimated that half of the U.S. population will meet criteria for a DSM diagnosis at some point in their lives. There are indications that mental health problems are even more prevalent in these underserved populations. While many primary care physicians are professionally comfortable treating mild to moderate mood and anxiety disorders, they often do not believe that they are qualified to treat more severe conditions such as bipolar disorder, schizophrenia, personality disorders, and most childhood mental health conditions. However, patients with these conditions routinely present to primary care providers.

An ethical principle guiding both medical and mental health professionals is that one should not provide services outside the bounds of ones' competence and professional training. This very fundamental issue is in conflict with the clinical needs of many patients seen in primary care and presents a very real dilemma to physicians. Primary care physicians struggle about whether to treat significant psychiatric conditions instead of referring to a mental health professional. The difficulties accessing the mental health system and issues of patient coverage for specialty mental health care are weighed against the possibility of providing suboptimal treatment in the primary care setting. In cases where the physician has referred a patient to a psychiatrist, but the patient must wait multiple months for an appointment, should the primary provider make a "best guess" diagnosis and initiate a similarly tentative treatment? This second issue also arises in countries such as Canada which have universal health care systems. In many of these countries, specialty care is particularly scarce and difficult to access and primary care providers are "stretched" to fill in this gap.

Primary care physicians have varying levels of comfort with mental health issues which is partly dependent on their training and experience. For example, in the United States, behavioral sciences are commonly part of the medical school curriculum as well as the residency training in family medicine, internal medicine, and pediatrics. However in many 
developing countries, such as Southeast Asia, Africa, Latin America, behavioral science and psychiatry are not taught in much detail, if at all (Searight and Gafford, 2006). As a result, when dealing with psychiatric issues, many physicians will be practicing outside the bounds of their competence. The only instance in which this is ethically permitted in an emergency. Again, the ethical dimensions of prudent judgment and balancing beneficence and nonmaleficence, together with open conversations with the patient about this dilemma to optimize their autonomy, may assist the provider in resolving these dilemmas.

\section{Conclusion: Ethics and the ambiguity of primary care mental health}

Ambiguity and lack of certainty, while present in all areas of medicine and mental health, are particularly prominent in primary care. The majority of patients in this setting are seen for self-limiting conditions that are unlikely to be life-threatening.

Medically unexplained symptoms are very common in primary care. While some of these patients meet psychiatric criteria for somatization disorder, most of them do not meet this formal threshold. However, at the same time, these patients are distressed about their symptoms, certainly functionally impaired, and at risk of receiving unnecessary and possibly harmful test procedures. Finally, they consume a good deal of health resources (Heijmans, olde Hartman, van Weel-Baumgarten et al., 2011).

Kroenke and Mangelsdorf (1989) identified the 14 most common symptom complaints presented in primary care settings over a three year period. These symptoms included headache, fatigue, joint and limb pain, and diarrhea. Of these presenting complaints, only about $15 \%$ could be linked to an established "organic" cause. While many of these concerns are likely to be related to life stress, they are typically treated as "medical" conditions. In fact, there is evidence that while most people experience many of these symptoms, those who bring these complaints to physicians have higher levels of anxious and dysphoric mood. As Goldstein (1990) noted, outpatient primary care requires a good deal of intuitive as well as scientific thought:

With uncertainty all around me, I sometimes long for the security that science appears to offer. Unfortunately science can no longer offer the comfort that I need. Positivism has long since given way to probability. Modern science has discarded traditional notions of certainty, but the applied sciences fail to fully absorb the message. An ordered, determinate universe of accurate diagnosis and definitive treatment will always be just beyond my grasp. My patients' fears fall through the cracks of the probabilistic certainty that remains (Goldstein, 1990, page 28).

Given the reality of ambiguity and the blurry boundaries between psychiatric and nonpsychiatric conditions with the attendant urgency to "do something" for the primary care patient, the physician genuinely struggles daily with an undercurrent of ethical tension. Making the picture even cloudier is the presence of "subclinical" psychiatric syndromes (Searight, 2010). For example some patients do not meet formal diagnostic criteria for either a mood or anxiety disorder but have symptoms of both conditions (Roy-Byrne, Katon, \& Broadhead, et al., 1994). This mixed condition is also associated with a greater number of physical symptoms, disability, and a greater likelihood of developing a major psychiatric disorder (Roy-Byrne, Katon, Broadhead, et al. 1994). There are few clear treatment guidelines for these sub-syndromal conditions. 
Another area of ambiguity with ethical implications is assessment of cognitive impairment in the elderly. While primary care is probably one of the most common settings for detection of cognitive deterioration in the elderly, these conditions are often ambiguous as well. Diagnosis is primarily based upon clinical history and mental status testing. Mild cognitive impairment, a "transitional zone" (Olazaren, Torrero, Cruz, et al., 2011) between the cognitive decline associated with normal aging and dementia of Alzheimer's type, raises a number of ethical issues of early diagnosis, and the patient's right to know. While MCI was initially believed to be a relatively benign condition, recent research indicates that about 5 to $10 \%$ of these patients per year convert to a dementia diagnosis. After 10 years, $50 \%$ of MCI patients will have converted. However, the remaining 50\% will have remained at the same level of cognitive functioning and in a few cases have even improved. In a recent study involving 31 months of follow-up of patients with $\mathrm{MCI}$, nearly $60 \%$ converted to normal cognitive functioning (Olazaran, et al., 2011). It is highly probable that changes in social circumstances and or the presence of mood or anxiety disorders plays a significant role in many of these patients' baseline level of cognitive impairment. From an ethical perspective, what should the provider say to MCI patients? Should they and their families be informed of the possible outcome? Is the predictive value of MCI so equivocal that the potential harm of informing patients and family members outweighs any benefit from the knowledge gained?

These are the types of "on the ground" ethical dilemmas that shape primary care practice. As Goldstein (1990) notes, primary care dilemmas are complex-both ethically and clinically:

"... to the seasoned clinician, the most interesting variety of knowledge comes not from unilateral action, but from negotiation between the physician and patient, leading to adequate enough agreement to allow them to venture upon a course of therapy. This therapeutic knowledge and its creation are inseparable; the process and product are intertwined. In fact, as the epithet implies, the creation of this knowledge is in itself a therapeutic act. (Goldstein, 1990; p. 26)

\section{References}

American Medical Association. (2001). Principles of Medical Ethics with Annotations for Psychiatry. Washington DC: Author.

American Psychiatric Association. (2006). The Diagnostic and Statistical Manual of Mental Disorders-IV-TR. Washington DC, American Psychiatric Press.

American Psychological Association (2002). Ethical Principles of Psychologists and Code of Conduct. Washington DC: Author.

Barrett, J. E., Barrett, J.A., Oxman, T.E. \& Gerber, P.D. (1988). The prevalence of psychiatric disorders in a primary care practice. Archives of General Psychiatry 45: 1100-1106.

Beauchamp, T.L. \& Childress, J.F. (2009). Principles of Biomedical Ethics (Sixth Edition). New York: Oxford.

Bryan, C.J. \& Rudd, M.D. (2011). Managing Suicide Risk in Primary Care. New York: Springer

Cwikel, J. Feinson, M \& Lerner,Y. (2008). Prevalence and risk factors of threshold and subthreshold psychiatric disorders in primary care. Social Psychiatry and Social Epidemiology 43: 184-191. 
Goldstein, J., H. (1990). Desperately seeking science: The creation of knowledge in family practice. Hastings Center Report 20(6). 26-29

Heijmans, M., olde Hartman, T.C., van Weel-Baumgarten, E., Dowrick, C., Lucassen, P. L., \& van Weel, C. (2011). Experts' opinions on the management of medically unexplained symptoms in primary care. A qualitative analysis of narrative reviews and scientific editorials. Family Practice, 28, 444-455.

Himelhoch, S. M. Ehrenreich., S. (2007). Psychotherapy by primary care providers: Results of a national survey. Psychosomatics 48(4): 325-330.

Kessler, R.C., Demler, O., Frank, R.G., Olfson, M. et al. (2005). U.S. prevalence and treatment of mental disorders: 1990-2003. New England Journal of Medicine, 352; 2515-2523.

Kroenke, K. \& Mangelsdorf, A.D. (1989). Common symptoms in ambulatory care: Incidence, evaluation, therapy, and outcome. American Journal of Medicine, 86, 262-266.

Kroenke, K., Spitzer, R.L., Williams, J.B.W., Monahan, P.O., Lowe, B. (2007). Anxiety disorders in primary care: Prevalence, impairment, comorbidity, and detection. Annals of Internal Medicine, 146, 317-325.

Koocher, G.P. \& Keith-Spiegel, P. (2008). Ethics in Psychology and the Mental Health Professions. New York: Oxford,

Mayes, R., Bagwell, C., Erkulwater, J.L (2009). Medicating Children: AD/HD and Pediatric Mental Health. Cambridge MA: Harvard University Press.

Olazaran, J., Torrero, P., Cruz, I. et al. (2011). Mild cognitive impairment and dementia in primary care: the value of medical history. Family Practice, 28, 385-392.

Pellegrino, E. \& Thomasma, D. (1998). For the Patient's Good: The Restoration of Beneficence in Health Care. New York: Oxford.

Roberts, L.W., Battaglia, J., \& Epstein, R.S. (1999). Frontier ethics: Mental health care needs and ethical dilemmas in rural communities. Psychiatric Services, 50, 497-503.

Roy-Byrne, P., Katon, W., , Brodhead, W., Lepine, J. P., Richard, J., Brantley, P. J., Russo, J., et al. (1994). Subsyndromal (mixed) anxiety and depression in primary care. Journal of General Internal Medicine, 9, 507-512.

Ruijs, C., Kerkhof, A., van de rWal, G., \& Onwuteaka-Philipsen, B. (2011). Depression and explicit requests for euthanasia in end-of-life cancer patients in primary care in the Netherlands: A longitudinal, prospective study. Family Practice, 28, 393-399.

Searight, H.R. (1991). Assessing patient competence for medical decision-making. American Family Physician, 45, 751-759.

Searight, H.R. (1997). The Tarasoff Warning and the duty to protect: Implications for family medicine. Journal of Aggression, Maltreatment, \& Trauma, 1(2), 153-168

Searight, H.R. (2010). Practicing Psychology in Primary Care. New York and Berlin: Hogrefe and Huber.

Searight, H.R. \& Campbell, D.C. (1993). Patient-physician sexual contact: Ethical dilemmas and practical guidelines. Journal of Family Practice, 36, 647-653.

Searight, H.R. \& Gafford, J. (2006). Behavioral science education and the international medical graduate. Academic Medicine, 81: 164-170.

Searight, H.R., Gafford, J. \& Evans, S. (2005). Attention deficit hyperactivity disorder. In M. Mengel \& P. Schwiebert (Eds.), Family Medicine: Ambulatory Care \& Prevention (Fourth Edition) (pp. 612-628). New York: McGraw-Hill. 
Searight, H.R. \& Montooth, A. (2008). Regaining decisional capacity during the hospital course: A narrative case with clinical implications. Archives of Psychiatry and Psychotherapy, 4, 47-55.

Sugarman, J. (2000). Ethics in Primary Care. New York: McGraw-Hill.

Tan, J., PAsserini, G., \& Stewart, A. (2007). Consent and confidentiality in clinical work with young people. Clinical Child Psychology and Psychiatry, 12, 191-210.

Ullom-Minnich, P.D. \& Kallial, K.J. (1993). Physicians' strategies for safeguarding confidentiality: The influence of practice and community characteristics. Journal of Family Practice, 37, 445-448.

Wang, P.S., Demler, O., Olfson, M., Pincus, H.A., Wells, K.B., Kessler, R.C. (2006). Changing profiles of service sectors used for mental health care in the United States. American Journal of Psychiatry, 163; 1187-1198.

World Health Organization (2011). Mental Health Atlas. Geneva: WHO. 


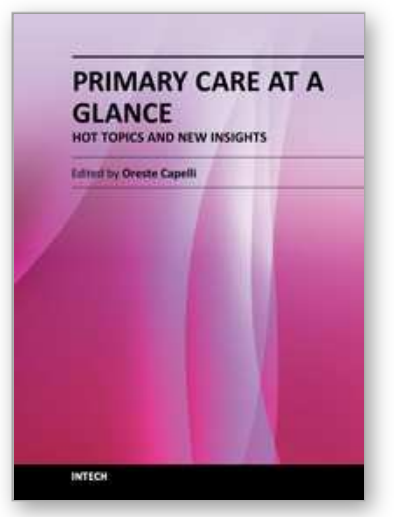

\author{
Primary Care at a Glance - Hot Topics and New Insights \\ Edited by Dr. Oreste Capelli
}

ISBN 978-953-51-0539-8

Hard cover, 446 pages

Publisher InTech

Published online 27, April, 2012

Published in print edition April, 2012

"Both among scientists and clinical practitioners, some find it easier to rely upon trivial explanations, while others never stop looking for answers". With these surprising words, Augusto Murri, an Italian master in clinical medicine, reminds us that medical practice should be a continuous journey towards knowledge and the quality of care. The book brings together contributions by over 50 authors from many countries, all around the world, from Europe to Africa, from Asia to Australia, from North to South America. Different cultures are presented together, from those with advanced technologies to those of intangible spirituality, but they are all connected by five professional attributes, that in the 1978 the Institute of Medicine (IOM) 1 stated as essentials of practicing good Primary Care: accessibility, comprehensiveness, coordination, continuity and accountability. The content of the book is organized according to these 5 attributes, to give the reader an international overview of hot topics and new insights in Primary Care, all around the world.

\title{
How to reference
}

In order to correctly reference this scholarly work, feel free to copy and paste the following:

Russell H. Searight (2012). Ethics and the Practice of Primary Care Psychiatry, Primary Care at a Glance - Hot Topics and New Insights, Dr. Oreste Capelli (Ed.), ISBN: 978-953-51-0539-8, InTech, Available from: http://www.intechopen.com/books/primary-care-at-a-glance-hot-topics-and-new-insights/practicing-behavioralmedicine-in-primary-care-professional-and-ethical-dilemmas

\section{INTECH}

open science | open minds

\author{
InTech Europe \\ University Campus STeP Ri \\ Slavka Krautzeka 83/A \\ 51000 Rijeka, Croatia \\ Phone: +385 (51) 770447 \\ Fax: +385 (51) 686166 \\ www.intechopen.com
}

\author{
InTech China \\ Unit 405, Office Block, Hotel Equatorial Shanghai \\ No.65, Yan An Road (West), Shanghai, 200040, China \\ 中国上海市延安西路65号上海国际贵都大饭店办公楼 405 单元 \\ Phone: +86-21-62489820 \\ Fax: +86-21-62489821
}


(C) 2012 The Author(s). Licensee IntechOpen. This is an open access article distributed under the terms of the Creative Commons Attribution 3.0 License, which permits unrestricted use, distribution, and reproduction in any medium, provided the original work is properly cited. 